\title{
Prevalence of frailty and associated factors among Saudi community-dwelling older adults: a cross-sectional study
}

\author{
Bader A. Alqahtani ${ }^{1 *}$, Aqeel M. Alenazi ${ }^{1}$, Mohammed M. Alshehri ${ }^{2}$ Ahmed M. Osailan', Saud F. Alsubaie ${ }^{1}$ and \\ Mohammed A. Alqahtani ${ }^{3}$
}

\begin{abstract}
Background: Prevalence of frailty has been previously established in different Western countries; however, the prevalence and the burden of in the aging populations of Saudi Arabia has not been examined. Therefore, the aim of this study was to examine the prevalence of frailty, and associated factors among Saudi older population.

Methods: The study included a total of 486 community-dwelling elderly adults aged 60 years and over living in the Riyadh area. This study took place from August 2019 to June 2020. The prevalence of frailty was determined using the Fried's frailty phenotype. Association between sociodemographic features and clinical factors and frailty was estimated by Odds Ratio and confidence intervals (OR, IC 95\%) using a multinomial logistic regression model.

Results: The overall prevalence of pre-frailty and frailty were 47.3 and $21.4 \%$, respectively. The following factors were associated with being frail: age (OR: 6.92; 95\%Cl 3.11-15.41); living alone (OR: 2.50; 95\%Cl: 1.12-5.59); had more chronic conditions (OR: 1.96; 95\%Cl: 1.16-3.30); and cognitive impairment (OR: 7.07; 95\%Cl: 3.92-12.74).
\end{abstract}

Conclusions: The Compared with other populations, the prevalence of frailty and pre-frailty in the Riyadh region of Saudi Arabia was high. The implications of frailty in this population should be discussed in future study.

Keywords: Frailty, Fried's frailty, Pre-frail, Saudi Arabia, Older adults

\section{Introduction}

The aging population in Saudi Arabia will increase drastically over the next few decades. According to the United Nations estimates, the Saudi older population will increase from $5.6 \%$ in 2017 to $22.9 \%$ by 2050 [1]. With the increasing number of elderly people in Saudi Arabia, it places more burden to the healthcare system due to the high prevalence of comorbidities that needs close supervision and continuous care, such as diabetes, arthritis, cardiovascular diseases, and aging related conditions (e.g. frailty).

\footnotetext{
* Correspondence: dralqahtaniba@gmail.com

'Department of Health and Rehabilitation sciences, Prince Sattam Bin Abdulaziz University, Al-Kharj 11942, Kingdom of Saudi Arabia

Full list of author information is available at the end of the article
}

Aging has been associated with deterioration in different body systems which include musculoskeletal, cardiovascular, sensory, and cognition [2-4]. In addition, frailty has been related to aging, which can lead to increased risk of falling, greater vulnerability to adverse outcomes, increased functional limitations, and institutionalization [5-7]. Due to the current significant growth in elderly population in Saudi Arabia, the topic of frailty becomes more important now than ever [8].

Frailty is a clinical geriatric syndrome characterized by an excess vulnerability to adverse health outcomes $[9,10]$. Frailty has become one of the serious public health issue in the geriatric population $[11,12]$. A recent meta-analysis of studies from different populations has reported that the

(C) The Author(s). 2021 Open Access This article is licensed under a Creative Commons Attribution 4.0 International License, which permits use, sharing, adaptation, distribution and reproduction in any medium or format, as long as you give appropriate credit to the original author(s) and the source, provide a link to the Creative Commons licence, and indicate if changes were made. The images or other third party material in this article are included in the article's Creative Commons licence, unless indicated otherwise in a credit line to the material. If material is not included in the article's Creative Commons licence and your intended use is not permitted by statutory regulation or exceeds the permitted use, you will need to obtain permission directly from the copyright holder. To view a copy of this licence, visit http://creativecommons.org/licenses/by/4.0/ The Creative Commons Public Domain Dedication waiver (http://creativecommons.org/publicdomain/zero/1.0/) applies to the data made available in this article, unless otherwise stated in a credit line to the data. 
prevalence of frailty varied from $4 \%$ in Chinese older adults to 51\% among older adults in Cuba [13].

Different measurements have been used to assess frailty [13]. Although, a gold standard measure has not been established yet, the Fried's frailty phenotype is one of the most widely used measurements to assess frailty [14].The Fried's frailty phenotype was put forth by Fried et al. using data from the Cardiovascular Health Study (CHS) [15]. Using this index, older adults are categorized as robust, pre-frail and frail based on five indicators include: unintentional weight loss, exhaustion, hand grip weakness, walking speed, and the level of physical activity. Investigators have demonstrated that the Fried's frailty phenotype has been associated with falls, hospitalizations, disability and death [11].

Frailty is considered as a dynamic condition, with proper interventions frailty can be altered or improved (i.e. frail elderly can improve to become pre-frail or robust). However, without proper intervention, a deterioration for older adults may occur and become definitely more frail and susceptible to disability [16]. By taking the aforementioned facts into consideration, assessing the prevalence of frailty and its associated factors will help in building future plans to decrease the burden of frailty through implementing targeted interventions in early stages. Although numerous studies have been done on frailty in different countries, frailty status among Saudi older adults is unknown. Therefore, the main purpose of the current study was to investigate the prevalence of frailty, and examine the association between frailty and sociodemographic and associated clinical factors in Saudi older adults.

\section{Materials and methods}

\section{Study design and participants}

This study was a community based cross-sectional study carried out in the Riyadh region specifically in Alkharj city, from August 2019 to June 2020. The estimated total population of the city in 2020 was about 425,300. With a great economic significance and up-to-date administration, Alkharj is one of the Kingdom's main hubs. The city is rich in its valuable natural resources, has a broad geographical area and demographic diversity. Older adults aged 60 years and older who lives in Alkharj city were recruited to take part in the current study. Recruitment was accomplished mainly by advertising in media and local community and cooperation with local residential communities (i.e., social centers, residential district committees). All participants provided a written informed consent before enrolling in the present study. The study was approved by the ethical committee at Prince Sattam bin Abdulaziz University in accordance with the guidelines of the Helsinki Declaration for medical research involving human participants. Participants were included if they were aged $\geq 60$ years. Participants were excluded if they were non-Saudi, had any acute disease or unstable medical condition that may affect the ability of answering the questionnaire proposed or complete the objective evaluation. More details about the participants enrollment are shown in Fig. 1.

\section{Study sample}

The sample size for study participants was calculated using previously published formula for prevalence studies [17]. We used a prevalence of $28 \%$ from a previous

Older adults were approached from Riyadh region and invited to participate in the study $(\mathrm{N}=531)$

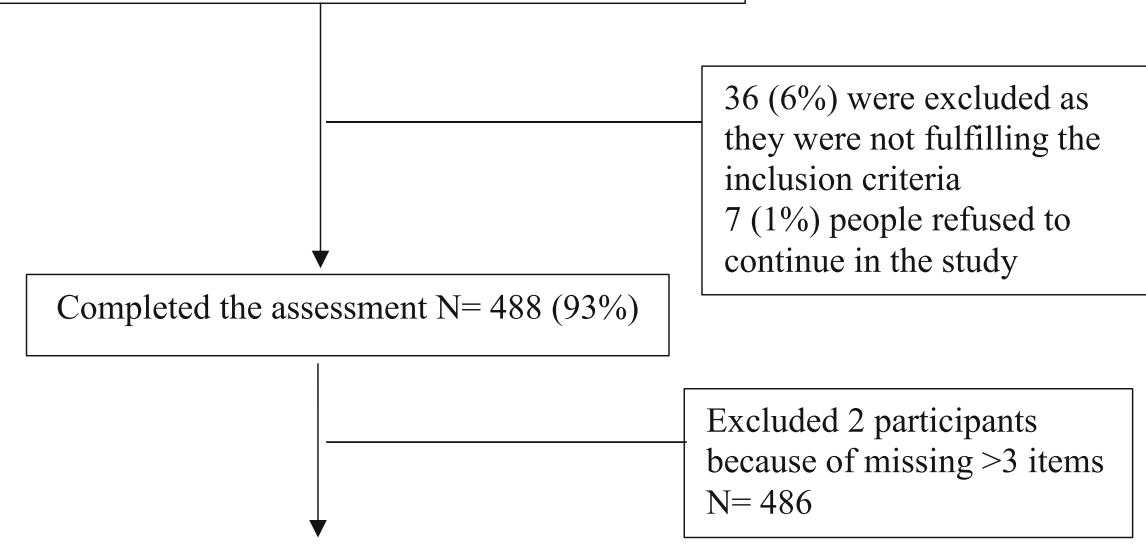

Final analysis $\mathrm{N}=486(99 \%)$

Fig. 1. Flow chart of participants' enrollment 
pilot study that was done on small sample size [18], and the desired precision was set at $4 \%$, with $95 \%$ confidence interval. Therefore, the final required sample was a total of 486 participants.

\section{Measurements}

The Fried's frailty phenotype was used to define and measure frailty in our study. The final score was based on the presence of 5 components: weight loss (measured by a self-report of unintentional weight loss of 10 pounds or more in the last year), exhaustion (defined by the participants responses as "I felt that everything I did was an effort" and "I could not get going" to questions adopted from the Center for Epidemiological Studies Depression (CES-D) scale), slow waling speed (measured by time spent to walk $15 \mathrm{ft}(4.57 \mathrm{~m})$, adjusted for gender and height), muscle weakness (measured by grip strength, using JAMAR PLUS ${ }^{\circ}$ digital hand dynamometer (Sam-mons Preston, Bolingbrook, IL, USA). Two trained physical therapists collected the strength data and the average of the peak force of the three measurements for the dominant hand was calculated by kilograms $(\mathrm{kg})$. The calibration of hand dynamometer was tested periodically during the testing Grip strength data was stratified by gender and Body Mass Index (BMI), and low physical activity (assessed by using subject responses to the Minnesota Leisure Time Activities Questionnaire) [15]. Each component was assigned a score of 0 or 1 . Participants were classified into 3 groups based on total score: 0 as robust, 1 to 2 as pre-frail, 3 or more as frail [15]. The Arabic version of the Mini-Mental State Examination (MMSE) was used to examine the cognitive function in the current sample [19]. The MMSE scores range from 0 to 30, with lower scores indicate poor cognitive function. A cutoff score of $<24$ was used to identify participants with cognitive impairment [20]. Sociodemographic data include gender, age, marital status, living arrangements, education level were collected. Information on chronic conditions was collected using a self-report. Finally, the BMI was estimated as weight $(\mathrm{kg}) /$ height $\left(\mathrm{m}^{2}\right)$. These measurements were obtained by trained physical therapists.

\section{Statistical analysis}

Data was analyzed using statistical software Stata version 15.1 (Stata Corp, College Station, TX). For continuous sociodemographic variables the mean and standard deviation were reported, and percentages were used for categorical variables. Normality of the included variables was assessed using Kolmogorov-Smirnov test and the data were normally distributed. One-way analysis of variance was used to compare baseline characteristics between frailty, pre-frailty and robust groups for continuous variables and chi-square test was used for categorical variables. Variables with $p$-value $<0.10$ on the univariaable analysis were then selected for multinomial regression analysis. A multinomial logistic regression model was constructed to examine the association between sociodemographic characteristics and clinical factors and frailty groups. The robust group was used as the reference group. Model goodness of fit was checked using the deviance statistic and the pseudo $R$ (Nagelkerke) and unadjusted odds ratio (OR) with the 95\% confidence intervals were reported. The level of statistical significance was set at $\alpha \leq 0.05$.

\section{Results}

A total of 486 participants were recruited in the current study. Table 1 shows the basic demographic and clinical characteristics of the participants. The average age of our sample was 71 years (range $60-89$ years). Sixty-five percent $(317 / 486)$ of the participants were male. The prevalence of frailty and its components are presented in Table 2. A total of $21.4 \%$ of participants were frail (females, 22.7\%), $47.3 \%$ were pre-frail (females, 51.5\%), and $31.2 \%$ were robust (females, 32.2\%). Females reported higher prevalence of exhaustion (35.3\%), weakness (36.2\%), and low physical activity (32.8\%) as shown in Table 2.

Table 3 show the results of association between the participants' sociodemographic characteristics and frailty status in adjusted and unadjusted multinomial regression models, with robust participants as a reference group. Significant associations were found for all variables that were included in the model except for gender. Frail participants were older (OR: 6.92; 95\%CI 3.11-15.41), were more likely to live alone (OR: 2.50 ; $95 \% \mathrm{CI}$ : $1.12-$ 5.59), had more chronic conditions (OR: 1.96; 95\%CI: 1.16-3.30), and had lower cognitive function (OR: 7.07; 95\%CI: 3.92-12.74) than those who were robust. In the unadjusted model, live alone (OR: 2.15 ; $95 \% \mathrm{CI}$ : $1.05-$ 4.39), had more chronic conditions (OR: 0.59; 95\%CI: $0.37-0.95$ ), and had lower cognitive function (OR: 2.10; 95\%CI: 1.21-3.51) were associated with pre-frailty. Associations were remained significant after adjusting for gender and age.

\section{Discussion}

This study examined the prevalence of frailty in Saudi older adults and associated factors. Our findings showed that the overall prevalence of pre-frailty and frailty were 47.3 and $21.4 \%$, respectively. The current study also identified the associated factors for frailty including older age, living alone, having 3 or more comorbidities, and impaired cognitive status. Although several studies have investigated the prevalence of frailty in different countries, there is limited information of frailty in Saudi Arabia. It is imperative to understand the associated 
Table 1 Sociodemographic and clinical characteristics of the study sample according to frailty status

\begin{tabular}{|c|c|c|c|c|c|}
\hline \multirow[t]{2}{*}{ Variable } & \multirow{2}{*}{$\begin{array}{l}\text { Total } \\
\text { sample } \\
N=486 \\
\text { (\%) }\end{array}$} & \multicolumn{3}{|c|}{ Frailty Status, n (\%) } & \multirow[t]{2}{*}{$p$} \\
\hline & & Robust & Pre-frail & Frail & \\
\hline \multicolumn{6}{|l|}{ Age groups } \\
\hline $60-69$ & $218(44.8)$ & $79(36.2)$ & $117(53.6)$ & $22(10.1)$ & \multirow[t]{3}{*}{$<0.001$} \\
\hline $70-79$ & $198(40.7)$ & $59(29.8)$ & $84(42.4)$ & $55(27.8)$ & \\
\hline$\geq 80$ & $70(14.4)$ & $14(20.0)$ & $29(41.4)$ & $27(38.6)$ & \\
\hline \multicolumn{6}{|l|}{ Gender } \\
\hline Male & $317(65.2)$ & $102(32.2)$ & $143(45.1)$ & $72(22.7)$ & \multirow[t]{2}{*}{0.384} \\
\hline Female & $169(34.7)$ & $50(29.6)$ & $87(51.5)$ & $32(18.9)$ & \\
\hline \multicolumn{6}{|l|}{ Education } \\
\hline No formal education & $286(61.3)$ & $93(32.5)$ & $128(44.7)$ & $65(22.7)$ & \multirow[t]{3}{*}{$<0.001$} \\
\hline Primary school & $119(24.4)$ & $39(36.8)$ & $58(54.7)$ & $9(7.5)$ & \\
\hline Middle school or more & $81(16.6)$ & $14(17.3)$ & $37(45.7)$ & $30(37.0)$ & \\
\hline \multicolumn{6}{|l|}{ Marital status } \\
\hline Married & $298(61.3)$ & $107(35.9)$ & $144(48.3)$ & $47(15.8)$ & \multirow[t]{2}{*}{$<0.001$} \\
\hline Single/widowed/divorced & $188(38.7)$ & $45(23.9)$ & $86(45.7)$ & $57(30.3)$ & \\
\hline \multicolumn{6}{|l|}{ Living arrangement } \\
\hline Living with others & $425(87.4)$ & $141(33.2)$ & $197(46.3)$ & $87(20.5)$ & \multirow[t]{2}{*}{0.051} \\
\hline Living alone & $61(12.6)$ & $11(18.0)$ & $33(54.1)$ & 17 (27.9) & \\
\hline \multicolumn{6}{|l|}{ Number of chronic conditions } \\
\hline None & $115(23.6)$ & $46(40.0)$ & $59(51.3)$ & $10(8.7)$ & \multirow[t]{3}{*}{$<0.001$} \\
\hline 1 & $110(22.6)$ & $26(23.6)$ & $66(60.0)$ & $18(16.4)$ & \\
\hline 2 or more & $261(53.7)$ & $80(30.6)$ & $105(40.2)$ & $76(29.1)$ & \\
\hline Grip strength, mean (SD) & 486 & $19.3(8.8)$ & $16.9(9.8)$ & $6.66(5.8)$ & $<0.001$ \\
\hline BMI $\left(\mathrm{Kg} / \mathrm{m}^{2}\right)$, mean $(\mathrm{SD})$ & 486 & $27.5(4.8)$ & $26.0(4.9)$ & $23.7(4.8)$ & $<0.001$ \\
\hline
\end{tabular}

health changes amongst Saudi population since the incidence of chronic health issues in Saudi Arabia differ to other countries in middle east. To our knowledge, this study provided first findings about frailty status using reliable and valid measurement and analyzed via structured methods among Saudi population.
The results of our study indicated that the prevalence of frailty in people aged 60 years or older in Saudi Arabia is $21.4 \%$. This prevalence is slightly higher than most of other studies that found the prevalence of frailty in several different countries between 4 and 16\% [21-24]. On the other hand, a number of previous studies have

Table 2 Prevalence of frailty status and its components

\begin{tabular}{llll}
\hline & Male $(n=317) \%(\mathrm{Cl})$ & Female $(n=169) \%(\mathrm{Cl})$ & Total $(n=486) \%(\mathrm{Cl})$ \\
\hline Frailty status & & & $21.4(17.9-25.2)$ \\
$\quad$ Frail & $22.7(18.4-27.6)$ & $18.9(13.7-25.5)$ & $47.3(42.9-51.7)$ \\
$\quad$ Pre-frail & $45.1(39.6-50.6)$ & $51.5(43.9-58.9)$ & $31.2(27.2-35.5)$ \\
$\quad$ Robust & $32.2(27.2-37.5)$ & $29.5(23.1-36.9)$ & $11.5(8.9-14.6)$ \\
Frailty components & & & $34.5(30.4-38.9)$ \\
$\quad$ Weight loss & $11.4(8.3-15.40)$ & $11.8(7.7-17.6)$ & $23.6(20.1-27.6)$ \\
Exhaustion & $35.3(30.2-40.8)$ & $33.1(26.4-40.6)$ & $31.6(27.6-35.9)$ \\
$\quad$ Slow gait speed & $22.7(18.4-27.6)$ & $25.4(19.4-32.5)$ & $31.1(27.1-35.3)$ \\
$\quad$ Weakness & $36.2(31.1-41.2)$ & $23.1(17.3-30.1)$ & $27.8(21.5-35.1)$ \\
Low physical activity & $32.8(27.8-38.2)$ & & \\
\hline
\end{tabular}


Table 3 Association between sociodemographic characteristics and frailty status in adjusted and unadjusted multinomial regression models

\begin{tabular}{|c|c|c|c|c|}
\hline \multirow[t]{3}{*}{ Variable } & \multicolumn{2}{|l|}{ Unadjusted model } & \multicolumn{2}{|l|}{ Adjusted model } \\
\hline & Robust vs pre-frail & Robust vs frail & Robust vs pre-frail & Robust vs frail \\
\hline & RRR (95\% Cl) & RRR $(95 \% \mathrm{Cl})$ & $\operatorname{RRR}(95 \% \mathrm{Cl})$ & RRR $(95 \% \mathrm{Cl})$ \\
\hline \multicolumn{5}{|l|}{ Age groups } \\
\hline $60-69$ & Ref. & Ref. & Ref. & Ref. \\
\hline $70-79$ & $0.96(0.62-1.49)$ & $3.35(1.83-6.10)$ & $0.95(0.61-1.48)$ & $3.36(1.83-6.10)$ \\
\hline$\geq 80$ & $1.40(0.69-2.82)$ & $6.92(3.11-15.41)$ & $1.37(0.68-2.70)$ & $7.04(3.15-15.70)$ \\
\hline \multicolumn{5}{|l|}{ Gender } \\
\hline Men & Ref. & Ref. & Ref. & Ref. \\
\hline Women & $0.81(0.52-1.24)$ & $1.10(0.64-1.88)$ & $0.81(0.53-1.25)$ & $1.21(0.69-2.12)$ \\
\hline \multicolumn{5}{|l|}{ Living alone } \\
\hline No & Ref. & Ref. & Ref. & Ref. \\
\hline Yes & $2.15(1.05-4.39)$ & $2.50(1.12-5.59)$ & $2.21(1.07-4.58)$ & $2.01(1.06-4.62)$ \\
\hline \multicolumn{5}{|c|}{3 or more chronic conditions } \\
\hline No & Ref. & Ref. & Ref. & Ref. \\
\hline Yes & $0.59(0.37-0.95)$ & $1.96(1.16-3.30)$ & $0.61(0.37-0.98)$ & $2.27(1.30-3.95)$ \\
\hline \multicolumn{5}{|c|}{ Cognitive status } \\
\hline Normal & Ref. & Ref. & Ref. & Ref. \\
\hline Impaired & $2.10(1.21-3.51)$ & 7.07 (3.92-12.74) & $2.21(1.26-3.85)$ & $5.45(2.91-10.21)$ \\
\hline
\end{tabular}

shown that the prevalence of frailty can be even higher. One study conducted in Cuba and found that the prevalence rate reached about $51 \%$ of the elderly [13].

The differences in prevalence reported by previous studies may be driven by methodological differences such as the age of participants as well as the population of the study; Studies have found that the prevalence of frailty is higher in those who reside in medical care centers than in the general community [21-25]. Studies also differed in the method of identifying of frailty; one approach of finding the prevalence of frailty is to follow Fried's frailty criteria [15], which is used in most studies, including our study. In contrast, few studies have adopted the cumulative deficits scores criteria which depends on the accumulative number of deficits in different organs of the body as an indicator of frailty [26].

The prevalence of pre-frailty was found to be $47.3 \%$, which is consistent with the results of other studies [23, 27-30]. However, the prevalence of pre-frailty is relatively high and should be considered as an indication of future frailty, and prevention programs should be established early.

The results of our study were consistent with results of several studies that have reported that the prevalence of frailty is strongly associated with cognitive impairment [23, 31-34]. Further, a number of studies have found that the presence of frailty is a significant predictor of future cognitive impairment [33, 34]. Similar to many studies, our study found that the prevalence of frailty is associated with having three or more chronic conditions [23, 31-34]. Our study also found an association between frailty and living alone, and this relationship is not clear because a few numbers of studies have looked at this relationship. However, living alone in Saudi Arabia may not be a common factor in older adults due to cultural differences when compared to other countries. Therefore, we selected this explanatory variable to examine the association between living alone and frailty status, and it was a significant association. This will add to the literature about Saudi Arabia for further research to understand the reasons behind this association such as diet, exercise, psychological, and other factors.

The prevalence of frailty increased sharply with increasing age as expected and reported in several studies [23, 25, 28, 31, 32, 35]. On the contrary, there was no difference between male and female in the prevalence of frailty, while several studies have indicated that the prevalence of frailty is higher in female [27, 31, 32, 35].

According to the General Authority for Statistics in Saudi Arabia, it was noticed that there is increase in the ratio of Saudi citizens who are at least 65 years old [36]. Therefore, as the population of older people in Saudi Arabia increase, prevalence of frailty will undoubtedly increase. This may result in a significant increase in hospital admissions and prolonged length of stay at the hospital. 
National Health Service in the United Kingdom reported high increase in older people ( 75 years old and above) hospitalization from 2,308,480 in 2000 up to 3, 837,990 in 2010 [37, 38], were older people with frailty represented a large proportion of these admissions. Furthermore, Frail people have high susceptibility for hospital re-admission in a short period of time [39]. It was also found that the hospitalization period was longer [40], and mortality rate was higher [41], in frail people than non-frail people.

Given the dearth of the mentioned evidence and the prevalence of frailty in Saudi Arabia reported in the present study, it is crucial to develop strategies and intervention to alter or reduce frailty. Interventions should be aimed to reduce frailty in order to cut the costs of prolonged hospitalization, hospital re-admission, and other associated comorbidities. Using Fried's frailty phenotype score as a measure of frailty status in clinics is one the first steps that can allow early identification of frailty status and the associated factors as well, which eventually, lead to better planning of future strategies and intervention at a population level either to prevent, reduce or to invert frailty.

Several limitations in this study should be recognized. Although Riyadh region is the largest diverse community in Saudi Arabia, there is a need to assess the prevalence of frailty status in all regions of Saudi Arabia to allow generalizability. It has been reported that several medications correlated with frailty status such as hypnotics, analgesics, and laxatives [42]. In addition, some mediations are prescribed to decrease the frailty symptoms [43]. Thus, there is a need to control for medications to strengthen the results of future researches. The crosssectional design of this study is another limitation that limit causality relationship. Although this design is considered a limitation in population-based research, our study identified the associated factors with frailty status, and this can be achieved by cross-sectional design. Since there is a limited evidence about frailty in Saudi Arabia, we need to examine the prevalence first and look at the associated factors with this condition. Then, when we have data and evidence, we can identify predictors for frailty in this population using longitudinal design. Other variables should be considered in future studies such as falls and hospitalization, depressive symptoms, functional capacity, and, health perception. Number of outcomes in this study were based on self-reported outcomes which might not be sensitive enough to present the accurate associations of frailty status in Saudi population. Some of domains in the frailty status might be overestimated by self-reported measures [44]. Therefore, we recommend using objective measures to accurately represent domains related frailty status in future research. Finally, depression and anxiety symptoms are highly associated with frailty status in general population [45]. We did not control for psychological symptoms which is needed to avoid extraneous effect on the prevalence and the relationship of frailty with demographics and clinical factors in Saudi population.

\section{Conclusions}

This study underlines the high level of prevalence of frailty and prefrailty among Saudi older adults. Both frailty and pre-frailty were associated with living alone, multiple comorbidities, and impaired cognitive function As the prevalence of frailty is high, we recommend raising awareness about this condition and its effect on older adults, and health practitioners. Assessment for fraility should be addressed in primary care settings. Future research should examine frailty across different regions in Saudi Arabia.

\section{Abbreviations}

CHS: Cardiovascular Health Study; CES-D: Epidemiological Studies Depression; BMI: Body Mass Index; MMSE: Mini-Mental State Examination; ANOVA: Analysis of variance; OR: Odds ratios

\section{Acknowledgements \\ The authors would like to thank the Prince Sattam bin Abdulaziz University for their support throughout this project.}

\section{Authors' contributions}

$B A$ and $A A$ conceived and designed the study. BA obtained funding. BA, and MAA helped with data collection. AA and MA helped with data interpretation. BA, AA, MA AO, SA, and MAA draft writing, read and approved the final version of the manuscript.

\section{Funding}

This study was supported by the deanship of scientific research at Prince Sattam bin Abdulaziz University under the project \# 2019/03/10805.

\section{Availability of data and materials}

The datasets used and/or analysed during the current study are available from the corresponding author on reasonable request.

\section{Declarations}

Ethics approval and consent to participate

This study has been approved by the ethical committee at Prince Sattam Bin Abdulaziz University (ethical approval number: RHPT/021/011). Participants provided written informed consent.

Consent for publication

Not applicable.

\section{Competing interests}

On behalf of all authors, the corresponding author states that there is no conflict of interest.

\section{Author details}

${ }^{1}$ Department of Health and Rehabilitation sciences, Prince Sattam Bin Abdulaziz University, Al-Kharj 11942, Kingdom of Saudi Arabia. ${ }^{2}$ Physical Therapy Department, Jazan University, Jazan, Kingdom of Saudi Arabia. ${ }^{3}$ College of Medicine, Dar Al Uloom University, Riyadh, Saudi Arabia. 
Received: 21 October 2020 Accepted: 9 March 2021

Published online: 17 March 2021

\section{References}

1. United Nations, Department of Economic and Social Affairs PD. World population ageing 2017: United Nations; 2017. p. 124. doi: ST/ESA/SER.A/ 348.

2. Segev-Jacubovski O, Herman T, Yogev-Seligmann G, Mirelman A, Giladi N, Hausdorff JM. The interplay between gait, falls and cognition: can cognitive therapy reduce fall risk? Expert Rev Neurother. 2011;11(7):1057-75. https:// doi.org/10.1586/ern.11.69.

3. Gangavati A, Hajjar I, Quach L, Jones RN, Kiely DK, Gagnon P, Lipsitz LA. Hypertension, orthostatic hypotension, and the risk of falls in a communitydwelling elderly population: the maintenance of balance, independent living, intellect, and zest in the elderly of Boston study. J Am Geriatr Soc 2011;59(3):383-9. https://doi.org/10.1111/j.1532-5415.2011.03317.x.

4. Lord SR. Visual risk factors for falls in older people. Age Ageing. 2006; 35(Suppl 2):ii42-5.

5. Ferrucci L, Guralnik JM, Studenski S, Fried LP, Cutler GB, Walston JD. Designing randomized, controlled trials aimed at preventing or delaying functional decline and disability in frail, older persons: a consensus report. J Am Geriatr Soc. 2004;52(4):625-34. https://doi.org/10.1111/j.1532-5415.2004. 52174.x

6. Ensrud KE, Ewing SK, Taylor BC, Fink HA, Stone KL, Cauley JA, Tracy JK, Hochberg MC, Rodondi N, Cawthon PM, for the Study of Osteoporotic Fractures Research Group. Frailty and risk of falls, fracture, and mortality in older women: the study of osteoporotic fractures. J Gerontol Ser A Biol Sci Med Sci. 2007;62(7):744-51. https://doi.org/10.1093/gerona/62.7.744.

7. Cawthon PM, Marshall LM, Michael Y, Dam TT, Ensrud KE, Barrett-Connor E, Orwoll ES, for the Osteoporotic Fractures in Men Research Group. Frailty in older men: prevalence, progression, and relationship with mortality. J Am Geriatr Soc. 2007;55(8):1216-23. https:/doi.org/10.1111/j.1532-5415.2007.01259.x

8. Nations U. World population ageing [highlights]. 2017. http://www.un.org/ en/development/desa/population/publications/pdf/ageing/WPA2017 Highlights.pdf. Accessed 20 Mar 2018.

9. Abellan van Kan G, Rolland Y, Andrieu S, Bauer J, Beauchet O, Bonnefoy M, Cesari M, Donini LM, Gillette-Guyonnet S, Inzitari M, Nourhashemi F, onder G, Ritz P, Salva A, Visser M, Vellas B. Gait speed at usual pace as a predictor of adverse outcomes in community-dwelling older people an internationa academy on nutrition and aging (IANA) task force. J Nutr Health Aging. 2009:13(10):881-9. https://doi.org/10.1007/s12603-009-0246-z http://www. ncbi.nlm.nih.gov/pubmed/19924348. Accessed 5 Feb 2015

10. Van Kan GA, Rolland Y, Bergman H, Morley JE, Kritchevsky SB, Vellas B. The I. A.N.A. task force on frailty assessment of older people in clinical practice. J Nutr Health Aging. 2008;12(1):29-37. https://doi.org/10.1007/BF02982161.

11. Rockwood K, Howlett SE, MacKnight C, Beattie BL, Bergman H, Hébert R, Hogan DB, Wolfson C, McDowell I. Prevalence, attributes, and outcomes of fitness and frailty in community-dwelling older adults: report from the Canadian study of health and aging. J Gerontol A Biol Sci Med Sci. 2004; 59(12):1310-7. https://doi.org/10.1093/gerona/59.12.1310.

12. Clegg A, Young J, lliffe S, Rikkert MO, Rockwood K. Frailty in elderly people. Lancet. 2013;381:752-62. https://doi.org/10.1016/S0140-6736(12)62167-9.

13. Siriwardhana DD, Hardoon S, Rait G, Weerasinghe MC, Walters KR. Prevalence of frailty and prefrailty among community-dwelling older adults in low-income and middle- income countries : a systematic review and meta-analysis. BMJ Open. 2018;8(3):1-17. https://doi.org/10.1136/bmjopen-2 017-018195.

14. Dent E, Kowal P, Hoogendijk EO. European journal of internal medicine frailty measurement in research and clinical practice : a review. Eur J Intern Med. 2016;31:3-10. https://doi.org/10.1016/j.ejim.2016.03.007.

15. Fried LP, Tangen CM, Walston J, Newman AB, Hirsch C, Gottdiener J, Seeman T, Tracy R, Kop WJ, Burke G, McBurnie MA. Frailty in older adults: evidence for a phenotype. J Gerontol A Biol Sci Med Sci. 2001;56(3):M14656. https://doi.org/10.1093/gerona/56.3.M146.

16. Liu CK, Fielding RA. Exercise as an intervention for frailty. Clin Geriatr Med. 2011:27(1):101-10. https://doi.org/10.1016/j.cger.2010.08.001

17. Pourhoseingholi MA, Vahedi M, Rahimzadeh M. Sample size calculation in medical studies. Gastroenterol Hepatol Bed Bench. 2013:6(1):14-7 http:// www.ncbi.nlm.nih.gov/pubmed/24834239.
18. Alqahtani BA, Nasser TA. Assessment of frailty in Saudi community-dwelling older adults: validation of measurements. Ann Saudi Med. 2019:39(3):197204. https://doi.org/10.5144/0256-4947.2019.197.

19. Albanna M, Yehya A, Khairi A, Dafeeah E, Elhadi AM, Rezgui L, al Kahlout SR, Yousif AEM, Uthman B, al-Amin $\mathrm{H}$. Validation and cultural adaptation of the Arabic versions of the mini-mental status examination - 2 and mini-cog test. Neuropsychiatr Dis Treat. 2017;13:793-801. https://doi.org/10.2147/NDT.S126825.

20. Dick JPR, Guiloff RJ, Stewart A. Mini-mental state examination in neurological patients. J Neurol Neurosurg Psychiatry. 1984;47(5):496-9. https://doi.org/10.1136/jnnp.47.5.496.

21. Kojima G, lliffe S, Taniguchi $Y$, Shimada H, Rakugi H, Walters K. Prevalence of frailty in Japan: a systematic review and meta-analysis. J Epidemiol. 2017; 27(8):347-53. https://doi.org/10.1016/j.je.2016.09.008.

22. Collard RM, Boter H, Schoevers RA, Oude Voshaar RC. Prevalence of frailty in community-dwelling older persons: a systematic review. J Am Geriatr Soc. 2012:60(8):1487-92. https://doi.org/10.1111/j.1532-5415.2012.04054.x.

23. Curcio C, Henao G, Gomez F. Frailty among rural elderly adults; 2014.

24. Xue QL. The frailty syndrome: definition and natural history. Clin Geriatr Med. 2011;27(1):1-15. https://doi.org/10.1016/j.cger.2010.08.009.

25. Payne CF, Wade A, Kabudula CW, et al. Prevalence and correlates of frailty in an older rural African population : findings from the HAALSI cohort study. BMC Geriatr. 2017;17(1):1-10. https://doi.org/10.1186/s12877-017-0694-y.

26. Mitnitski AB, Mogilner AJ, Rockwood K. Accumulation of deficits as a proxy measure of aging. Sci World J. 2001;1:323-36. https://doi.org/10.1100/tsw.2 001.58 .

27. Jürschik Giménez P, Escobar Bravo MÁ, Nuin Orrio C, Botigué Satorra T. Frailty criteria in the elderly: a pilot study. Aten Primaria. 2011;43(4):190-6. https://doi.org/10.1016/j.aprim.2010.03.020.

28. Garcia-Garcia FJ, Gutierrez Avila G, Alfaro-Acha A, Amor Andres MS, de Los Angeles de la Torre Lanza M, Escribano Aparicio MV, Humanes Aparicio S, Larrion Zugasti JL, Gomez-Serranillo Reus M, Rodriguez-Artalejo F, Rodriguez-Manas $L$. The prevalence of frailty syndrome in an older population from Spain. The Toledo study for healthy aging. J Nutr Health Aging. 2011;15(10):852-6. https://doi.org/10.1007/s12603-011-0075-8.

29. Ottenbacher KJ, Graham JE, Al Snih S, et al. Mexican Americans and frailty: findings from the hispanic established populations epidemiologic studies of the elderly. Am J Public Health. 2009;99(4):673-9. https://doi.org/10.2105/A JPH.2008.143958.

30. Espinoza SE, Hazuda HP. Frailty in older Mexican-American and EuropeanAmerican adults: is there an ethnic disparity? J Am Geriatr Soc. 2008;56(9): 1744-9. https://doi.org/10.1111/j.1532-5415.2008.01845.x

31. Aguilar-Navarro S, Gutiérrez-Robledo LM, García-Lara JMA, Payette $H$, Amieva $\mathrm{H}$, Avila-Funes JA. The phenotype of frailty predicts disability and mortality among Mexican community-dwelling elderly. J Frailty Aging. 2012; 1(3):111-7. https://doi.org/10.14283/jfa.2012.18.

32. de Albuquerque Sousa ACP, Dias RC, Maciel Álvaro CC, Guerra RO. Frailty syndrome and associated factors in community-dwelling elderly in Northeast Brazil. Arch Gerontol Geriatr. 2012;54(2):e95-e101. https://doi. org/10.1016/j.archger.2011.08.010

33. Yassuda MS, Lopes A, Cachioni M, Falcao DVS, Batistoni SST, Guimaraes W, Neri AL. Frailty criteria and cognitive performance are related: data from the Fibra study in Ermelino Matarazzo, Sao Paulo, Brazil. J Nutr Health Aging. 2012;16(1):55-61. https://doi.org/10.1007/s12603-012-0003-6.

34. Ávila-Funes JA, Pina-Escudero SD, Aguilar-Navarro S, Gutierrez-Robledo LM, Ruiz-Arregui L, Amieva H. Cognitive impairment and low physical activity are the components of frailty more strongly associated with disability. J Nutr Health Aging. 2011;15(8):683-9. https://doi.org/10.1007/s12603-0110111-8.

35. Fernandez-Bolaños M, Otero Á, Zunzunegui MV, et al. Sex differences in the prevalence of frailty in a population aged 75 and older in Spain. J Am Geriatr Soc. 2008;56(12):2370-1. https://doi.org/10.1111/j.1532-5415.2008. 02032.x.

36. General Authority for Statistics Saudi Arabia. Demographic survey. Demogr Surv. 2016;2016:208 https://www.stats.gov.sa/sites/default/files/en-demogra phic-research-2016_4.pdf\%5Cnhttps://www.stats.gov.sa/sites/default/files/endemographic-research-2016_4.pdf\%0Astats.gov.sa\%0Ahttp://www.e-stat.go. jp/SG1/estat/List.do?lid=000001112823.

37. Oo MT, Chan YP, Chamberlain H, Ho SF. Understanding clinical importance of frailty and designing a frailty assessment tool in acute hospitals. J Gerontol Geriatr Res. 2014;3(4):2. https://doi.org/10.4172/2167-7182.1000176. 
38. Aragon Aragon MJ, Castelli A, Gaughan J. Hospital Trusts productivity in the English NHS: uncovering possible drivers of productivity variations. PLoS One. 2017;12(8):e0182253. https://doi.org/10.1371/journal.pone.0182253.

39. Ekerstad N, Bylin K, Karlson BW. Early rehospitalizations of frail elderly patients - the role of medications: a clinical, prospective, observational trial. Drug Healthc Patient Saf. 2017;9:77-88. https://doi.org/10.2147/ DHPS.S139237.

40. Woodard J, Gladman J, Conroy S. Frail older people at the interface. Age Ageing. 2010;39(S1):i36

41. Nguyen AT, Nguyen TX, Nguyen TN, Nguyen THT, Thang P, Cumming R, Hilmer SN, Vu HT. The impact of frailty on prolonged hospitalization and mortality in elderly inpatients in Vietnam: a comparison between the frailty phenotype and the reported Edmonton frail scale. Clin Interv Aging. 2019; 14:381-8. https://doi.org/10.2147/CIA.S189122.

42. Chen CY, Wu SC, Chen $\mathrm{L}$, Lue BH. The prevalence of subjective frailty and factors associated with frailty in Taiwan. Arch Gerontol Geriatr. 2010; 50(Suppl 1):S43-7.

43. Matteini AM, Walston JD, Fallin MD, Bandeen-Roche K, Kao WHL, Semba RD, Allen RH, Guralnik J, Fried LP, Stabler SP. Markers of B-vitamin deficiency and frailty in older women. J Nutr Health Aging. 2008;12(5):303-8. https:// doi.org/10.1007/BF02982659

44. Chang Cl, Chan DC, Kuo KN, Agnes Hsiung C, Chen CY. Prevalence and correlates of geriatric frailty in a Northern Taiwan Community. J Formos Med Assoc. 2011;110(4):247-57. https://doi.org/10.1016/50929-6646(11)6003 7-5.

45. Mhaolain AMN, Fan CW, Romero-Ortuno R, Cogan L, Cunningham C, Kenny RA, Lawlor B. Frailty, depression, and anxiety in later life. Int Psychogeriatr. 2012;24(8):1265-74 http://ovidsp.ovid.com/ovidweb.cgi?T=JS\&PAGE= reference $\& D=e m e d 14 \& N E W S=N \& A N=365010879$.

\section{Publisher's Note}

Springer Nature remains neutral with regard to jurisdictional claims in published maps and institutional affiliations.

Ready to submit your research? Choose BMC and benefit from:

- fast, convenient online submission

- thorough peer review by experienced researchers in your field

- rapid publication on acceptance

- support for research data, including large and complex data types

- gold Open Access which fosters wider collaboration and increased citations

- maximum visibility for your research: over $100 \mathrm{M}$ website views per year

At $\mathrm{BMC}$, research is always in progress.

Learn more biomedcentral.com/submissions 